\title{
A Primer on Magnetic Resonance-Guided Laser Intersti- tial Thermal Therapy for Medically Refractory Epilepsy
}

\author{
Eun Jung Lee, M.D., 'Suneil K. Kalia, M.D., Ph.D., ${ }^{2,3}$ Seok Ho Hong, M.D., Ph.D. ${ }^{4}$ \\ Department of Neurosurgery, Seoul National University Hospital, Seoul, Korea \\ Division of Neurosurgery, ${ }^{2}$ Department of Surgery, Toronto Western Hospital, University of Toronto, Toronto, Canada \\ Krembil Research Institute, ${ }^{3}$ University Health Network, Toronto, Canada \\ Department of Neurological Surgery, ${ }^{4}$ Asan Medical Center, University of Ulsan College of Medicine, Seoul, Korea
}

\begin{abstract}
Epilepsy surgery that eliminates the epileptogenic focus or disconnects the epileptic network has the potential to significantly improve seizure control in patients with medically intractable epilepsy. Magnetic resonance-guided laser interstitial thermal therapy (MRgLITT) has been an established option for epilepsy surgery since the US Food and Drug Administration cleared the use of MRgLITT in neurosurgery in 2007. MRgLITT is an ablative stereotactic procedure utilizing heat that is converted from laser energy, and the temperature of the tissue is monitored in real-time by MR thermography. Real-time quantitative thermal monitoring enables titration of laser energy for cellular injury, and it also estimates the extent of tissue damage. MRgLITT is applicable for lesion ablation in cases that the epileptogenic foci are localized and/or deep-seated such as in the mesial temporal lobe epilepsy and hypothalamic hamartoma. Seizure-free outcomes after MRgLITT are comparable to those of open surgery in well-selected patients such as those with mesial temporal sclerosis. Particularly in patients with hypothalamic hamartoma. In addition, MRgLITT can also be applied to ablate multiple discrete lesions of focal cortical dysplasia and tuberous sclerosis complex without the need for multiple craniotomies, as well as disconnection surgery such as corpus callosotomy. Careful planning of the target, the optimal trajectory of the laser probe, and the appropriate parameters for energy delivery are paramount to improve the seizure outcome and to reduce the complication caused by the thermal damage to the surrounding critical structures.
\end{abstract}

Key Words : Drug resistant epilepsy · Hypothalamic hamartomas · Laser therapy · Anterior temporal lobectomy · Epilepsy, Temporal lobe.

\section{INTRODUCTION}

Epilepsy is a serious disabling neurological disorder affecting approximately $0.5-1 \%$ of the world's population, and seizures in one-third of the patients are refractory to medications despite a combination of at least two adequate anti-seizure drugs $^{10,23,24)}$. In these medically intractable patients, epilepsy surgery that eliminates the epileptogenic focus or disconnects the epileptic network has the potential to significantly improve seizure control in terms of frequency and severity and even enable the patients to achieve seizure freedom ${ }^{5}$. However, due to inadequate referral patterns and the erroneous per-

- Received : April 24, $2019 \bullet$ Revised : April 29, $2019 \bullet$ Accepted : April 29, 2019

- Address for reprints : Seok Ho Hong, M.D., Ph.D.

Department of Neurological Surgery, Asan Medical Center, University of Ulsan College of Medicine, 88 Olympic-ro 43-gil, Songpa-gu, Seoul 05505, Korea Tel : +82-2-3010-3568, Fax : +82-2-476-6738, E-mail : hongsound@gmail.com

This is an Open Access article distributed under the terms of the Creative Commons Attribution Non-Commercial License (http://creativecommons.org/licenses/by-nc/4.0) which permits unrestricted non-commercial use, distribution, and reproduction in any medium, provided the original work is properly cited. 
ception that "open" surgery may have substantial perioperative morbidity and potential neuropsychological deficit, surgery for epilepsy has been underutilized in patients who may have benefits from it. As part of an effort to develop minimally invasive surgical techniques with a potentially improved safety profile, magnetic resonance-guided laser interstitial thermal therapy (MRgLITT) has emerged as a viable treatment option for some patients with medically refractory epilepsy. MRgLITT is an ablative stereotactic procedure utilizing heat that is converted from laser energy, and the temperature of the tissue is monitored in real-time by MR thermography. It is now an established option for epilepsy surgery since the US Food and Drug Administration cleared the use of MRgLITT in neurosurgery in $2007^{5,12,25)}$. Here, we give an overview of the use of MRgLITT in epilepsy, compare the seizure outcome and complications between traditional open surgery and MRgLITT, and discuss important technical considerations.

\section{MR-GUIDED LASER ABLATION SYSTEM}

An MRgLITT system consists of a MR-compatible laser used in conjunction with MR thermography which allows for real-time thermal imaging of tissue ablation around the laser tip. Thermal energy delivered by LITT causes protein denaturation and cell death. The laser probe is a flexible catheter with a light-emitting tip and is covered with a cooling sheath. It is inserted directly into the targeted tissue using standard stereotactic procedures. Briefly the process of MRgLITT is as follows (Fig. 1) : first, a stereotactic frame or equivalent is applied to the patient's head and appropriate imaging is acquired for trajectory and ablation planning. In the operative environment, using a stereotactic device-fitted twisted drill, an MRcompatible bone anchor is positioned at the pre-planned entry point co-axial with the pre-planned trajectory to the target. If needed the patient is then transferred to the MR environment and the laser with variable diameter and type of cooling unit according to different manufacturers is inserted through the bone anchor and passed to the target. With the laser applica-
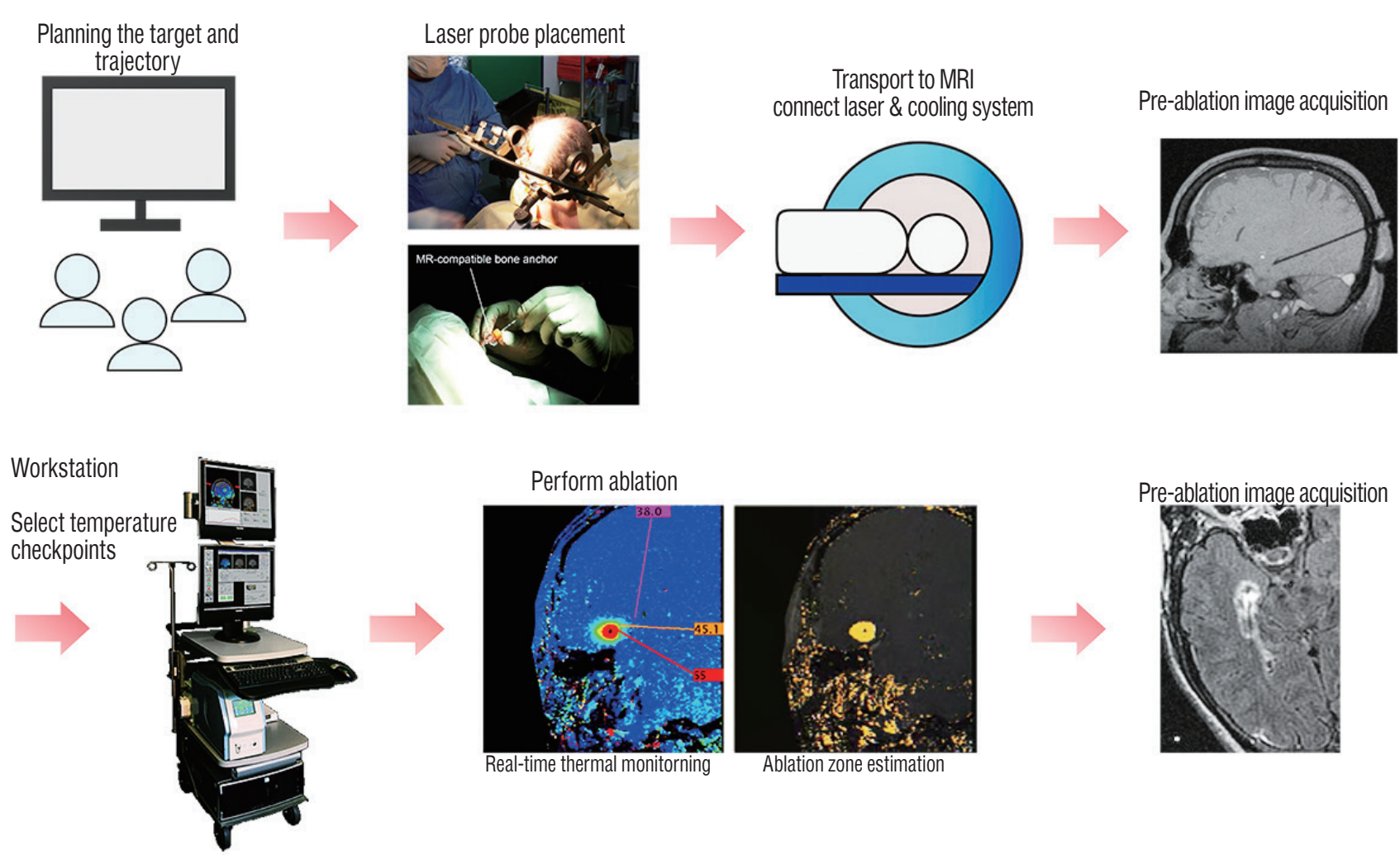

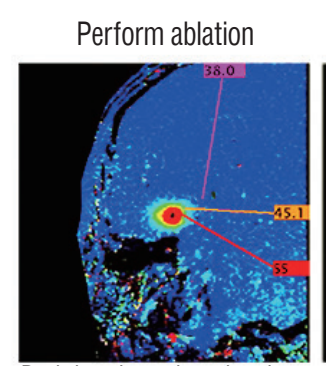

Real-time thermal monitorning

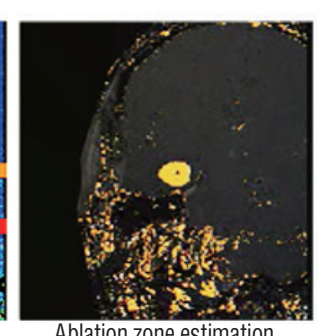

Ablation zone estimation

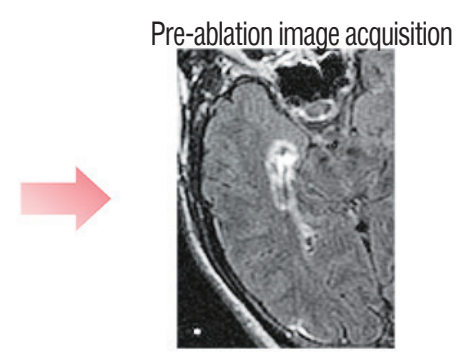

Fig. 1. Schematic illustration showing the workflow of the magnetic resonance-guided laser interstitial thermal therapy ${ }^{5,14)}$. Figures are modified with permission for use from Medtronic. 
tor being secured to the bone anchor, new MR scans are obtained to confirm the location of the laser probe. If the location is unsatisfactory, the optical fiber can be repositioned at this stage $\mathrm{e}^{3,5,14)}$. The laser applicator is connected to a laser energy source and a cooling system that helps to cool the laser probe and the surrounding tissue. Visualase ${ }^{\circledR}$ (Medtronic Inc., Lewiston, CO, USA) uses sterile room temperature saline circulating inside the sheath to cool the optical fiber, while the NeuroBlate ${ }^{\circledR}$ System (Monteris Medical, Winnipeg, Canada) cools the laser tip with pressurized $\mathrm{CO}_{2}$. The advantages of the MRgLITT system are first that the ablation procedure is guided by MR imaging, which verifies laser position and extent of ablation zone. Secondly, real-time quantitative thermal monitoring using MR thermography enables titration of laser energy for cellular injury, and it also estimates the extent of tissue damage. Using these prediction models, if the temperature of the surrounding tissue in "no-go" zones is predicted to exceed a predefined temperature limit, the laser may be deactivated, and thus allow for safe control of the ablation process. In general, the temperature limit in the target tissue around the laser probe is designed below $90^{\circ} \mathrm{C}$, while those of tissue at the borders of the desired ablation zone or critical structures are set below $48-50^{\circ} \mathrm{C}^{35)}$. The temperature at the edge of the ablation zone falls off sharply and thus is generally considered safe if the interface between the ablation zone and the surrounding tissues is more than $1 \mathrm{~mm}^{12,28)}$. If "heat sinks" such as large blood vessels and cerebrospinal fluid (CSF) spaces are in the vicinity of the target, the risk of thermal damage to the adjacent critical tissue is further reduced ${ }^{12)}$. "Heat sinks" can also make it challenging to obtain adequate rise in temperature of the intended target. Immediately after LITT, additional MR imaging is obtained to review the treated area. If satisfactory, the laser is removed, and the incisions are closed. This series of procedures is possible through local anesthesia and light sedation, although most centers perform this procedure under general anesthesia. Recently, some authors have reported experience on MRgLITT in epilepsy patients using the ClearPoint ${ }^{\circledR}$ system (MRI Interventions, Inc., Irvine, CA, USA) that allows for the entire surgical procedure to be performed utilizing real-time MR guidance in the MR imaging suite by providing a frameless stereotactic platform ${ }^{14,26,38)}$. This MR-guided frameless stereotactic platform is more time-efficient, reducing the mean anesthesia time by more than 100 minutes. However, the target error calculated by comparing the planned target to the actual position of the laser probe was reported ranging from 0.7 to $3.4 \mathrm{~mm}$ in the ClearPoint ${ }^{\circledR}$ system (MRI Interventions, Inc.). This level of accuracy is considered acceptable by some depending on the size of a target, but the accuracy of this frameless stereotactic platform needs to be further improved and verified so that the entire MRgLITT process can be performed more safely and reliably in the MR suite.

\section{INDICATION}

MRgLITT is a useful treatment option for lesion ablation in cases that the epileptogenic foci are localized and/or deepseated such as in the mesial temporal lobe epilepsy (MTLE) and hypothalamic hamartoma $(\mathrm{HH})$. Also, in focal cortical dysplasia and tuberous sclerosis complex having multiple discrete lesions, MRgLITT is advantageous for ablating multiple lesions without the need for multiple craniotomies (Table 1). In addition to lesionectomy, MRgLITT has also been applied to the disconnection surgery such as corpus callosotomy for medically refractory epilepsy. In general, MRgLITT may be considered for small lesions $\leq 2-3 \mathrm{~cm}$, however, it may still be an option for large deep-seated lesions such as $\mathrm{HH}$ and lesions located in the insular lobe ${ }^{12)}$. We focus on the use of MRgLITT in MTLE and $\mathrm{HH}$ patients to compare planning, considerations during procedure, and the seizure outcome between conventional open surgery and MRgLITT. Treatment outcomes of MRgLITT in other epilepsy diseases will also be briefly covered.

\section{MESIAL TEMPORAL LOBE EPILEPSY}

MTLE that originates in the hippocampus and/or amygdala is the most common epilepsy syndrome, affecting 27\% of epilepsy patients, and is also the leading cause of medically refractory seizures ${ }^{2,9,16)}$. In most MTLE patients ( 70\%), mesial temporal sclerosis (MTS) is observed on MR images ${ }^{3,9)}$, and the hippocampus is considered to be associated with the generation of epileptic discharge. MTLE can be treated surgically by resecting the epileptogenic focus, i.e., amygdala and hippocampus $^{9,10,36)}$. There are several types of open surgery for MTLE. Conventional anteromedial temporal lobectomy 
Table 1. Seizure outcomes and adverse effects after MRgLITT

\begin{tabular}{|c|c|c|c|c|}
\hline Study & $\begin{array}{l}\text { No. of patients } \\
\text { (No. of etiology) }\end{array}$ & $\begin{array}{c}\text { Age } \\
\text { (mean [range]) }\end{array}$ & Outcome & Adverse effect \\
\hline Gross et al. ${ }^{13)}(2018)$ & 58 (58 MTLE) & $40(16-67)$ & $\begin{array}{l}\text { Engel I, } 53.4 \% \text { ( } 60.5 \% \text { in patients } \\
\text { with MTS vs. } 33.3 \% \text { in patients } \\
\text { without MTS) }\end{array}$ & $\begin{array}{l}5 \text { VFD }(8.6 \%) \rightarrow 1 \text { persistent and } \\
\text { symptomatic, } 1 \mathrm{ICH}, 1 \mathrm{SDH}, 4 \\
\text { transient non-disabling partial CN } \\
\text { palsy } \rightarrow \text { completely recovered }\end{array}$ \\
\hline Kang et al. ${ }^{20)}(2016)$ & $\begin{array}{l}20 \text { (20 MTLE including } 17 \\
\text { MTS) }\end{array}$ & $38.9(11-66)$ & $\begin{array}{l}\text { Engel I, 55\% (11/20); improved: 65\% } \\
\quad(13 / 20)\end{array}$ & $\begin{array}{l}1 \text { edema with hemorrhage, } 1 \text { VFD, } \\
\text { transient 4th CN palsy }\end{array}$ \\
\hline Willie et al..$^{38)}(2014)$ & 13 (13 MTLE) & $32.6(16-64)$ & $\begin{array}{l}\text { Seizure free, } 54 \%(7 / 13) \text { in } \\
\text { MTLE/67\% (6/9) in MTS patients; } \\
\text { meaningful seizure reduction, } \\
77 \%(10 / 13)\end{array}$ & 1 VFD, 1 small SDH (evacuated) \\
\hline Wilfong and Curry ${ }^{37)}$ (2013) & $14(14 \mathrm{HH})$ & $7.8(2-20)$ & Seizure free, $86 \%$; improved, 100\% & $\begin{array}{l}1 \text { subclinical SAH not requiring } \\
\text { intervention }\end{array}$ \\
\hline Fayed et al. ${ }^{12)}(2018)$ & $\begin{array}{l}12 \text { (4 HH, } 3 \text { PVNH, } 2 \text { FCD, } \\
2 \text { TS, } 1 \text { MTS) }\end{array}$ & $11.1(2-22)$ & $\begin{array}{l}\text { Engel I, } 66.7 \% \text {, Engel II, 16.7\%, III, } \\
\qquad 16.7 \%\end{array}$ & $1 \mathrm{VFD}$ \\
\hline Lewis et al. ${ }^{28)}(2015)$ & $\begin{array}{l}17 \text { (12 FCD, } 5 \text { TS, } 1 \text { HH, } \\
1 \text { MTS, } 1 \text { Rasmussen } \\
\text { encephalitis, } 1 \text { tumor) }\end{array}$ & $15.3(5.9-20.6)$ & $\begin{array}{l}\text { Engel I, 41\% (7/17); Engel II, 6\% } \\
(1 / 17), \text { Engel III, 18\% (3/17); Engel } \\
\text { IV, 35\% (6/17) }\end{array}$ & $\begin{array}{l}2 \text { inaccurate fiber placement, failure of } \\
\text { the cooling mechanism } \\
\text { ( } \rightarrow \text { overheating, breakage of the fiber), } \\
\text { postablation edema }\end{array}$ \\
\hline Curry et al. ${ }^{5)}$ (2012) & $\begin{array}{l}5 \text { (MTS, } 2 \text { HH, FCD, cingulate } \\
\text { tuber/TS) }\end{array}$ & $10.6(5-16)$ & Seizure free, 100\% & $\begin{array}{l}\text { Transient short-term memory } \\
\text { dysfunction }(\mathrm{HH})\end{array}$ \\
\hline Esquenazi et al. ${ }^{11)}$ (2014) & $2 \mathrm{PVH}$ & 25,48 & Engel I, 100\% & $1 \mathrm{VFD}$ \\
\hline
\end{tabular}

MRgLITT : magnetic resonance-guided laser interstitial thermal therapy, MTLE : mesial temporal lobe epilepsy, MTS : mesial temporal sclerosis, VFD : visual field defect, ICH : intracranial hemorrhage, SDH : subdural hemorrhage, $\mathrm{CN}$ : cranial nerve, $\mathrm{HH}$ : hypothalamic hamartoma, $\mathrm{SAH}$ : subarachnoid hemorrhage, FCD : focal cortical dysplasia, TS : tuberous sclerosis, PVNH : periventricular nodular heterotopia

(ATL) consists of removal of variable amounts of the lateral temporal neocortex followed by resection of the amygdala and intraventricular hippocampal formation. Lateral temporal neocortex resection is usually performed 3.5 to $4 \mathrm{~cm}$ in length in the anterior-posterior direction from the temporal pole while preserving the superior temporal gyrus, and generally includes resection of the fusiform gyrus, which facilitates access to epileptogenic mesial temporal structures ${ }^{8,9}$. The treatment outcome of ATL is so satisfactory that $60-80 \%$ of MTLE patients reach seizure freedom at 1-year postoperatively and a worthwhile improvement in seizure control is attainable in an overall $95 \%$ rate of patients ${ }^{3,18,19)}$. However, conventional ATL whereby the optic radiation, temporal stem conveying language-related fasciculi, and fusiform and parahippocampal gyri are involved into resection, may cause some neurological sequelae such as visual field defect, language disturbance, and face recognition difficulties. Selective amygdalohippocampectomy (SAH) is performed by approaching the temporal horn of the lateral ventricle through the middle temporal gyrus and/or inferior temporal sulcus while sparing as much of the temporal neocortex as possible ${ }^{8}$. However, $\mathrm{SAH}$ also requires a process to resect a portion of the lateral temporal neocortex including the parahippocampal gyrus, which may contribute to neuropsychological sequelae ${ }^{3,8)}$. Transsylvian approach, in which the temporal horn of the lateral ventricle is accessed through the temporal stem after dissecting the Sylvian fissure, is known to result in neuropsychological outcomes similar to those of transcortical approach for $\mathrm{SAH}$, while phonemic fluency was significantly better in transcortical approach than transsylvian $\mathrm{SAH}^{30)}$. In contrast, MR-guided stereotactic laser amygdalohippocampotomy (SLAH) completely spares the neocortical structures and thus may mitigate the neuropsychological adverse effects ${ }^{7,82,39}$. Drane et al. ${ }^{8)}$ reported that none of the patients with MTLE experienced a decline of naming or famous face recognition after SLAH, while after open surgery, $95 \%$ of the patients ( 21 of 22 ) with dominant MTLE and $65 \%$ of the patients (11 of 17) with nondominant MTLE demonstrated declines in naming task and famous face 


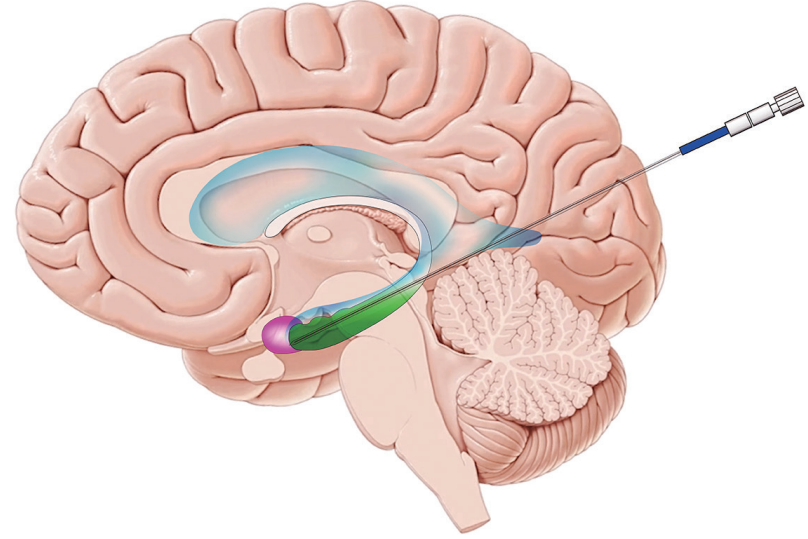

(A)

Fig. 2. Schematic depicting the target and the trajectory of laser probe for magnetic resonance-guided laser interstitial thermal therapy in patients with mesial temporal lobe epilepsy. Note the anatomical relationships between the ventricle (blue), hippocampus (green), and amygdala (pink). A: Sagittal view. B: Axial view.

recognition, respectively. The parieto-occipital region is generally selected as an entry point for SLAH when targeting the amygdala and the hippocampus (Fig. 2) ${ }^{3}$. A trajectory is carefully planned so that the laser probe may pass through the long axis of the hippocampus and amygdala while avoiding the sulci and vasculature. Concerning the hippocampus, the head to the body posteriorly to the level of the tectal plate is ideally included in thermal ablation. Given that the residual mesial hippocampal head has been known to be associated with poor outcome in seizure control ${ }^{18,20,38)}$, care should be taken in planning to ensure that the mesial temporal head is completely ablated. When the laser probe is placed too lateral within the hippocampal head, the mesial hippocampal head is likely to be untreated, while the optic radiation is subject to the thermal injury. On the other hand, a too medially located probe within the hippocampal head may induce thermal injury to the 3 rd and 4 th cranial nerves ${ }^{3}$. Therefore, it is crucial for the laser probe to be centered within the hippocampal head for both efficacy and safety in the axial plane. If necessary, re-ablation of residual tissue can be considered to achieve seizure freedom. Also, it is advisable to plan so that the trajectory does not pass with a steep angle in the sagittal plane. This steep trajectory may result in a probe tip which is placed too inferiorly resulting in incomplete ablation of the uncal apex and amygdala. For trajectories requiring the laser probe to pass through the ventricle, it is important to be aware that this may cause a deflection and resultant off-targeting ${ }^{299}$. Lastly, it is critical to plan that the probe does not pass too close to the lateral geniculate nucleus (LGN) to avoid the contralateral homonymous hemianopia caused by thermal injury to the LGN. An ablation is created ranging from 5 to $20 \mathrm{~mm}$ in diameter at the distal most point of the trajectory, and $3-5$ consecutive ablations are performed during the procedure while gradually withdrawing the laser fiber by $5-10 \mathrm{~mm}$. The total ablation volume is calculated by MR thermography, and the laser energy should be delivered with lower intensity as the probe moves back to avoid possible injury to the optic radiation and $\mathrm{LGN}^{3,29)}$. Seizure-free outcome (Engel Class I) after MRgLITT for MTLE has been reported to be around 53 to $65 \%$ while higher seizure freedom is achievable in the setting of MTS up to $73 \% \%^{13,18,27)}$. Although MRgLITT is not as beneficial with respect to seizure freedom when compared to rates provided by open surgery, in well-selected patients such as those with MTS, MRgLITT provides an excellent option for seizure control which is less invasive ${ }^{13,38}$. The most common neurological deficit following MRgLITT is visual field defects, which occurs ranging from 5 to $29 \%$ of patients. The type of visual field defect is mostly contralateral partial superior homonymous quadrantanopia due to thermal injury of the posterior optic radiation ${ }^{17,38)}$. Notably, patients with less intervening choroid plexus and cerebrospinal fluid space within the choroidal fissure, which employ protective effect against thermal 
injury, are known to be at higher risk of LGN injury ${ }^{17)}$. Other reported complications include headache, hematoma, and edema at the ablation site as well as transient cranial nerve palsies $^{20,25,38)}$. However, the incidence of hemorrhage after MRgLITT is reported to be low $(4 \%)^{3)}$. In addition, with appropriate perioperative treatment with dexamethasone, the risk of severe edema that may occur following thermal ablation may be mitigated.

\section{HYPOTHALAMIC HAMARTOMA}

$\mathrm{HH}$ is a non-neoplastic congenital malformation that develops in and/or around the hypothalamus between the infundibular recess and the mammillary bodies ${ }^{22)}$. Symptoms usually occur during early childhood. There are two clinical phenotypes depending on the attachment location of $\mathrm{HH}$ in the hypothalamus : if the $\mathrm{HH}$ arises in the region of the tuber cinereum or pituitary stalk, central precocious puberty develops and epilepsy is not usually associated with this. On the other hand, when the $\mathrm{HH}$ develops in the posterior region of the hypothalamus, in the region of the mammillary bodies, it results in gelastic seizure and secondary epilepsy with several neuropsychiatric symptoms such as developmental delay, cognitive deficit, and rage behavior. If the lesion is large enough to be broadly attached to both anterior and posterior regions of the hypothalamus, the patients can present with both epilepsy and precocious puberty. Epilepsy related to $\mathrm{HH}$ are mostly intractable to medical treatment ${ }^{4,21)}$, and endoscopic resection and/or disconnection of $\mathrm{HH}$ has been preferred to open surgery as a surgical approach to $\mathrm{HH}$, given the complexity of the open surgical approach to $\mathrm{HH}$ and the relatively high rates of complication. Endoscopic surgery accesses to $\mathrm{HH}$ through the ventricle, and disconnection is achieved by coagulating the border between hamartoma and hypothalamus using a monopolar coagulator or fiberoptic electrode of the laser. Seizure freedom rate after endoscopic dissection was reported ranging from 50 to $60 \%$ with reduction in seizure frequency $50 \%$ in over $90 \%$ of patients ${ }^{31,33,34)}$. Inadvertent handling of the endoscope can cause injury to the fornix, optic apparatus, or hypothalamus $^{34)}$. Moreover, endoscopic surgery requires a learning curve to acquire competency to manage challenging cases, and the frequent blurring of the lens during the surgery is cumbersome. Permanent memory loss after endoscopic dis- section of $\mathrm{HH}$ was reported to be less than $10 \%{ }^{31,33,34)}$. On the other hand, MRgLITT has become an effective and safe alternative to open and/or endoscopic surgery for $\mathrm{HH}^{1,32,37)}$. Indeed, $\mathrm{HH}$ is the most frequent indication (64.2\%) for MRgLITT in pediatric epilepsy ${ }^{15)}$. MR guided stereotactic procedure allows better access to the deep-seated hamartoma, without the need for any mechanical manipulation of critical structures, particularly fornices, and MR thermography provides sophisticated visualization of the border between the $\mathrm{HH}$ and the surrounding hypothalamus. The goal of the MRgLITT for $\mathrm{HH}$ is to completely disconnect $\mathrm{HH}$ from the hypothalamus and mammillothalamic tract rather than thermal coagulation of the entire mass. The therapeutic effect usually occurs immediately after the procedure ${ }^{15)}$. Curry et al. ${ }^{6}$ reported $93 \%$ freedom rate from gelastic seizures at 1 year after MRgLITT in 71 $\mathrm{HH}$ pediatric patients. This is a superior outcome compared to those of open or endoscopic surgery ${ }^{37)}$. Complications usually occur secondary to the thermal damage of the surrounding tissues, which includes memory impairment due to the injury of mammillary bodies, fornix, or mammillothalamic tract, as well as diabetes insipidus ${ }^{6,15)}$. However, these complications occur far less than any other open surgical technique. Setting a low-limit threshold for the critical structures will help prevent those complications, and Curry et al. ${ }^{6)}$ have recommended a low-temperature limit of $48^{\circ} \mathrm{C}$.

Meanwhile, stereotactic radiofrequency ablation is another less invasive ablative technique that can be performed under imaging guidance ${ }^{25)}$. However, in the radiofrequency system, the extent of ablation per one treatment session is much less compared to the MRgLITT system, thus multiple probe passes are needed. In addition, a lack of real-time feedback of the radiofrequency system on the extent of tissue ablation may cause imprecisely controlled energy delivery to the tissue, risking thermal injury to the critical surrounding structures.

\section{SUMMARY}

MRgLITT is a minimally invasive stereotactic procedure that ablates the epileptogenic foci using heat converted from the laser energy in conjunction with real time MR thermography showing a visualization of a tissue ablation zone. This enables precise energy titration, and it has become an established safe and effective alternative to open surgery for epilepsy pa- 
tients $^{14)}$. Particularly, MRgLITT may be considered as a firstline surgical option in pediatric patients with a deep-seated $\mathrm{HH}$, as it decreases the surgical morbidities and neurological deficits compared to the open surgery while yielding a superb seizure freedom rate. MRgLITT is also worth considering as a surgical option in patients with MTLE, as it offers favorable seizure outcomes comparable to open surgery and potentially reduces neuropsychologic complications. A small incision, fast recovery, short hospital stay are appealing advantages of MRgLITT from a patient perspective, especially in pediatric patients with medically intractable lesional epilepsy ${ }^{12)}$. It is important in such cases that as part of the informed consent process the patient understands that MRgLITT outcomes may be inferior for MTLE when compared with open surgery. It is possible however to consider open surgery after failed MRgLITT or consider MRgLITT to address residual hippocampus in the case of delayed seizure recurrence following open surgery. Careful planning of the target, the trajectory of the laser probe, and the parameters for energy delivery are essential to improve the seizure outcome and to reduce the complication caused by the thermal damage to the surrounding critical structures. However, there is still no established standard for the appropriate unit thermal energy per unit volume of ablation of tissue, and further research is needed to define it and set the parameters to deliver adequate laser energy to the tissues.

\section{CONFLICTS OF INTEREST}

No potential conflict of interest relevant to this article was reported.

\section{INFORMED CONSENT}

This type of study does not require informed consent.

\section{References}

1. Abla AA, Rekate HL, Wilson DA, Wait SD, Uschold TD, Prenger E, et al. : Orbitozygomatic resection for hypothalamic hamartoma and epilepsy: patient selection and outcome. Childs Nerv Syst 27 : 265-277, 2011
2. Berg AT, Shinnar S, Levy SR, Testa FM : Newly diagnosed epilepsy in children: presentation at diagnosis. Epilepsia 40 : 445-452, 1999

3. Bezchlibnyk YB, Willie JT, Gross RE : A neurosurgeon's view: laser interstitial thermal therapy of mesial temporal lobe structures. Epilepsy Res 142 : 135-139, 2018

4. Chibbaro S, Cebula H, Scholly J, Todeschi J, Ollivier I, Timofeev A, et al. : Pure endoscopic management of epileptogenic hypothalamic hamartomas. Neurosurg Rev 40 : 647-653, 2017

5. Curry DJ, Gowda A, McNichols RJ, Wilfong AA : MR-guided stereotactic laser ablation of epileptogenic foci in children. Epilepsy Behav 24 : 408-414, 2012

6. Curry DJ, Raskin J, Ali I, Wilfong AA : MR-guided laser ablation for the treatment of hypothalamic hamartomas. Epilepsy Res 142 : 131-134, 2018

7. Drane DL : MRI-Guided stereotactic laser ablation for epilepsy surgery: promising preliminary results for cognitive outcome. Epilepsy Res 142 : 170-175, 2018

8. Drane DL, Loring DW, Voets NL, Price M, Ojemann JG, Willie JT, et al. : Better object recognition and naming outcome with MRI-guided stereotactic laser amygdalohippocampotomy for temporal lobe epilepsy. Epilepsia 56 : 101-113, 2015

9. Engel J Jr, McDermott MP, Wiebe S, Langfitt JT, Stern JM, Dewar S, et al. : Early surgical therapy for drug-resistant temporal lobe epilepsy: a randomized trial. JAMA 307 : 922-930, 2012

10. Engel J Jr, Wiebe S, French J, Sperling M, Williamson P, Spencer D, et al. : Practice parameter: temporal lobe and localized neocortical resections for epilepsy: report of the Quality Standards Subcommittee of the American Academy of Neurology, in association with the American Epilepsy Society and the American Association of Neurological Surgeons. Neurology 60 : 538-547, 2003

11. Esquenazi $Y$, Kalamangalam GP, Slater JD, Knowlton RC, Friedman $E$, Morris SA, et al. : Stereotactic laser ablation of epileptogenic periventricular nodular heterotopia. Epilepsy Res 108 : 547-554, 2014

12. Fayed I, Sacino MF, Gaillard WD, Keating RF, Oluigbo CO : MR-guided laser interstitial thermal therapy for medically refractory lesional epilepsy in pediatric patients: experience and outcomes. Pediatr Neurosurg 53 : 322-329, 2018

13. Gross RE, Stern MA, Willie JT, Fasano RE, Saindane AM, Soares BP, et al. : Stereotactic laser amygdalohippocampotomy for mesial temporal lobe epilepsy. Ann Neurol 83 : 575-587, 2018

14. Ho AL, Sussman ES, Pendharkar AV, Le S, Mantovani A, Keebaugh AC, et al. : Improved operative efficiency using a real-time MRI-guided stereotactic platform for laser amygdalohippocampotomy. J Neurosurg 128 : 1165-1172, 2018

15. Hoppe C, Helmstaedter C : Laser interstitial thermotherapy (LiTT) in pediatric epilepsy surgery. Seizure, 2018 [Epub ahead of print]

16. Jallon P, Loiseau P, Loiseau J : Newly diagnosed unprovoked epileptic seizures: presentation at diagnosis in CAROLE study. Coordination Active du Reseau Observatoire Longitudinal de l' Epilepsie. Epilepsia 42 : 464-475, 2001

17. Jermakowicz WJ, Ivan ME, Cajigas I, Ribot R, Jusue-Torres I, Desai MB, 
et al. : Visual deficit from laser interstitial thermal therapy for temporal lobe epilepsy: anatomical considerations. Oper Neurosurg (Hagerstown) 13 : 627-633, 2017

18. Jermakowicz WJ, Kanner AM, Sur S, Bermudez C, D'Haese PF, Kolcun JPG, et al. : Laser thermal ablation for mesiotemporal epilepsy: analysis of ablation volumes and trajectories. Epilepsia 58 : 801-810, 2017

19. Josephson CB, Dykeman J, Fiest KM, Liu X, Sadler RM, Jette N, et al. : Systematic review and meta-analysis of standard vs selective temporal lobe epilepsy surgery. Neurology 80 : 1669-1676, 2013

20. Kang JY, Wu C, Tracy J, Lorenzo M, Evans J, Nei M, et al. : Laser interstitial thermal therapy for medically intractable mesial temporal lobe epilepsy. Epilepsia 57 : 325-334, 2016

21. Kerrigan JF, Ng YT, Chung S, Rekate HL : The hypothalamic hamartoma: a model of subcortical epileptogenesis and encephalopathy. Semin Pediatr Neurol 12 : 119-131, 2005

22. Kumar R, Yadav J, Sahu JK, Tripathi M, Ahuja C, Dayal D : Episodes of prolonged "trance-like state" in an infant with hypothalamic hamartoma. Ann Pediatr Endocrinol Metab 24 : 55-59, 2019

23. Kwan P, Arzimanoglou A, Berg AT, Brodie MJ, Allen Hauser W, Mathern $G$, et al. : Definition of drug resistant epilepsy: consensus proposal by the ad hoc Task Force of the ILAE Commission on Therapeutic Strategies. Epilepsia 51 : 1069-1077, 2010

24. Kwan P, Brodie MJ : Early identification of refractory epilepsy. $\mathbf{N}$ Engl J Med $342:$ 314-319, 2000

25. LaRiviere MJ, Gross RE : Stereotactic laser ablation for medically intractable epilepsy: the next generation of minimally invasive epilepsy surgery. Front Surg $3: 64,2016$

26. Larson PS, Starr PA, Bates G, Tansey L, Richardson RM, Martin AJ : An optimized system for interventional magnetic resonance imaging-guided stereotactic surgery: preliminary evaluation of targeting accuracy. Neurosurgery 70(1 Suppl Operative) : 95-103; discussion 103, 2012

27. Le S, Ho AL, Fisher RS, Miller KJ, Henderson JM, Grant GA, et al. : Laser interstitial thermal therapy (LITT): seizure outcomes for refractory mesial temporal lobe epilepsy. Epilepsy Behav 89 : 37-41, 2018

28. Lewis EC, Weil AG, Duchowny M, Bhatia S, Ragheb J, Miller I : MR-guided laser interstitial thermal therapy for pediatric drug-resistant lesional epilepsy. Epilepsia 56 : 1590-1598, 2015
29. Li K, Vakharia VN, Sparks R, Franca LGS, Granados A, McEvoy AW, et al. : Optimizing trajectories for cranial laser interstitial thermal therapy using computer-assisted planning: a machine learning approach. Neurotherapeutics 16 : 182-191, 2019

30. Lutz MT, Clusmann H, Elger CE, Schramm J, Helmstaedter C : Neuropsychological outcome after selective amygdalohippocampectomy with transsylvian versus transcortical approach: a randomized prospective clinical trial of surgery for temporal lobe epilepsy. Epilepsia 45 : 809 816, 2004

31. Ng YT, Rekate HL, Prenger EC, Wang NC, Chung SS, Feiz-Erfan I, et al. : Endoscopic resection of hypothalamic hamartomas for refractory symptomatic epilepsy. Neurology 70 : 1543-1548, 2008

32. North RY, Raskin JS, Curry DJ : MRI-guided laser interstitial thermal therapy for epilepsy. Neurosurg Clin N Am 28 : 545-557, 2017

33. Rekate HL, Feiz-Erfan I, Ng YT, Gonzalez LF, Kerrigan JF : Endoscopic surgery for hypothalamic hamartomas causing medically refractory gelastic epilepsy. Childs Nerv Syst 22 : 874-880, 2006

34. Shim KW, Park EK, Kim DS : Endoscopic treatment of hypothalamic hamartomas. J Korean Neurosurg Soc 60 : 294-300, 2017

35. Tovar-Spinoza Z, Carter D, Ferrone D, Eksioglu Y, Huckins S : The use of MRI-guided laser-induced thermal ablation for epilepsy. Childs Nerv Syst 29 : 2089-2094, 2013

36. Wiebe S, Blume WT, Girvin JP, Eliasziw M; Effectiveness, Efficiency of Surgery for Temporal Lobe Epilepsy Study Group : A randomized, controlled trial of surgery for temporal-lobe epilepsy. N Engl J Med 345 : 311-318, 2001

37. Wilfong AA, Curry DJ : Hypothalamic hamartomas: optimal approach to clinical evaluation and diagnosis. Epilepsia 54 Suppl 9 : 109-114, 2013

38. Willie JT, Laxpati NG, Drane DL, Gowda A, Appin C, Hao C, et al. : Realtime magnetic resonance-guided stereotactic laser amygdalohippocampotomy for mesial temporal lobe epilepsy. Neurosurgery 74 : 569 584; discussion 584-585, 2014

39. Zolamorgan $S$, Squire LR, Amaral DG, Suzuki WA : Lesions of perirhinal and parahippocampal cortex that spare the amygdala and hippocampalformation produce severe memory impairment. J Neurosci 9 : 43554370, 1989 